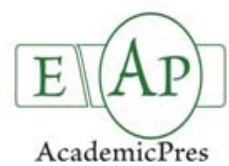

\title{
Investigation on Phenolic and Aroma Compounds of Table Grapes from Romania
}

\author{
Mihai-Lucian LUNG ${ }^{1 *}$, Doru PAMFIL ${ }^{1}$, Nastasia POP ${ }^{1}$, Corina CATANA ${ }^{1}$, Simona-Laura \\ LAZAR $^{1}$, Simone GIACOSA ${ }^{2}$, Fabrizio TORCHIO ${ }^{3}$, Alessandra FERRANDINO², \\ Susana RÍO SEGADE ${ }^{2}$, Luca ROLLE ${ }^{2}$
}

\author{
'University of Agricultural Sciences and Veterinary Medicine,CaleaMănăstur3-5, 400372,Chij-Napoca, Romania:mihai2lung@yahoo.com ("correspondingauthor); \\ dpamfi@usamvchi.ro;nastpop@yahoo.com; cornacatana@usamvchij.r;;azansimonalaura@gmail.com \\ ${ }^{2}$ UniversitàdegliStudidi Torino, Dipartimento diScienze Agrarie, Forestalie Alimentari LangoPaolo Braccini2, 10095 Grugliasco(TO), Italy; simone.giacosa@unito.it; \\ alessandraferrandino@unito.itssusanariosegade@unito.it;ucarolle@unito.it \\ 35stituto di Enologiae Ingegneria Agro-Alimentare, Università Cattolicadel Sacro Cuore,Via Emilia Parmense 84, 29122 Piacenza, Italy; fabrizio.torchio@unicatt.it
}

\begin{abstract}
The chemical composition of Romanian table grape varieties was determined to evaluate their phenolic and aroma profiles because they are factors useful for the variety characterization and consumer acceptance. Two white table grapes ('Aromat de Iaşi' and 'Timpuriu de Cluj') and two red table grapes ('Napoca' and 'Someşan') were studied. The phenolic composition of berry skins and seeds was determined using spectrophotometric methods. The profile of anthocyanins and hydroxycinnamoyl tartaric acids (HCTs), and the content of trans-resveratrol were determined in the skins using high-performance liquid chromatographic (HPLC) methods. Free volatile compounds were quantified by gas chromatography/mass spectrometry (GC/MS). A different phenolic and aromatic composition was found in the varieties studied. Among white grapes, 'Aromat de Iaşi' stands out for the great number of aroma compounds, and 'Timpuriu de Cluj' showed high contents of polyphenols, particularly oligomeric flavanols in skins and seeds (1,171 and $1,189 \mathrm{mg} \mathrm{kg}^{-1}$, respectively) and total skin HCTs (181.6 $\left.\mathrm{mg} \mathrm{kg}^{-1}\right)$. The red variety 'Napoca' had high contents of total anthocyanins $\left(380 \mathrm{mg} \mathrm{kg}^{-1}\right)$ and total skin HCTs $\left(183.2 \mathrm{mg} \mathrm{kg}^{-1}\right)$, and it is characterized by high percentages of acylated anthocyanin derivatives (28.5\%) and trans-caffeoyltartaric acid forms (58.8\%). 'Someşan' grapes showed high contents of free volatile compounds, particularly of 1-hexanol, (Z)-3-hexen-1-ol and $(E)$-2-hexenoic acid $\left(167.0,59.4\right.$ and $\left.167.0 \mu \mathrm{g} \mathrm{kg}^{-1}\right)$. These results may contribute to the knowledge of Romanian table grapes perspective and to a better exploitation of these varieties.
\end{abstract}

Keywords: Romanian table grape varieties, polyphenolics, anthocyanins, hydroxycinnamoyl tartaric acids, flavor compounds

\section{Introduction}

Romania is a viticultural country that is member of the International Organization of Vine and Wine (OIV) from 1927, with areas planted with vines accounting for 176 thousands ha in 2014, of which 7183 ha for table grape varieties (INSSE, 2015). A large number of grape biotypes and cultivars are found mainly in the western part of Romania, representing an important source of biodiversity. This variability is also a valuable source for obtaining products with specific local features, which are desired by the consumers (Dobrei et al., 2009).

Romanian table grape varieties were not enough exploited and studied, indeed they deserve more attention. The 'Aromat de Iaşi’ cultivar was obtained by open pollination of 'Tămâioasă românească, and homologated in 1980. 'Timpuriu de Cluj' was obtained by controlled sexual hybridization between 'Crâmpoşie' and 'Frumoasă de Ghioroc' varieties. Homologated in 1979, this variety stands out for earliness, resistance to frost and high fertility. 'Napoca' was obtained in 1989 by hybridization of 'Alphonse Lavallee' $\times$ ('Regina viilor' × 'Muscat
Hamburg') varieties. The 'Someșan' variety was obtained in 1987 by self-pollination of one hybrid elite from 'Muscat Hamburg' × 'Regina viilor'.

Grape phenolic substances or polyphenols include many classes of compounds such as phenolic acids, colored anthocyanins, flavanols, flavonols and stilbenes (Crupi et al., 2012; Urcan et al., 2016). Phenolic compounds content in grapes is variable depending on the variety, grape maturation, climatic conditions, geographical factors and cultural practices (Topalovic et al., 2012). These compounds are responsible for nutraceutical properties of grapes, and health benefits of their consumption have been reported in many studies (Baiano and Terracone, 2011; Georgiev et al., 2014; Topalovic et al., 2012). Biologically active phytonutrients found in grapes have neuroprotective, antimicrobial, cardioprotective and antiaging properties (Heim et al., 2002; Xia et al., 2010).

In table grapes, aroma is a key attribute for consumers. In particular, the free forms of volatile compounds are directly involved in the sensory perception, and therefore it could be interesting to assess the aromatic potential of table grape varieties. 
Alcohols, aldehydes, acids, terpenes, norisoprenoids and benzene compounds have been identified and quantified in table grapes. The aromatic composition is mainly influenced by the variety, but other factors such as ripening, environmental conditions and cultural practices may have a role in the presence of these compounds in the grape berry (Fenoll et al., 2009; Rolle et al., 2015).

The present study represents an initial contribution to the chemical characterization of four table grape varieties from Romania ('Aromat de Iaşi', 'Timpuriu de Cluj', 'Napoca' and 'Somesan'). To our knowledge, there is no scientific literature regarding these varieties, and therefore it could be important to assess their peculiarities in the phenolic and aroma profiles. Total phenols, flavanols, anthocyanins, hydroxycinnamoyl tartaric acids and resveratrol were determined at harvest using spectrophotometric and high-performance liquid chromatographic (HPLC) methods. Free volatile compounds were quantified by gas chromatography/mass spectrometry (GC/MS).

\section{Materials and Methods}

Grapesamples

The study was carried out in 2011 on 4 table grape cultivars (Vitis vinifera L.). Two Romanian white table grape varieties ('Aromat de Iaşi' and 'Timpuriu de Cluj'), and two Romanian red table grape varieties ('Napoca' and 'Someşan') were chosen. The grapes were collected in the collection vineyard of the University of Agricultural Sciences and Veterinary Medicine from Cluj-Napoca, Romania, when soluble solids concentration was higher than $14^{\circ}$ Brix. This collection vineyard was planted at $2.5 \times 1 \mathrm{~m}$, vertical shoot-positioned, and cane pruned.

For each cultivar, five hundred berries were randomly sampled directly from at least ten plants, from different parts of the cluster (shoulders, middle, and bottom) and with different solar exposure (shaded and sun-exposed). Sets of berries were randomly selected for the determination of the chemical composition of each cultivar. The remaining berries, subdivided into three replicates, were used for determining Brix degrees with a refractometer (Alla France, Chemillé, France) in the grape must obtained by manual crushing and centrifugation.

\section{Chemical analysis}

Solvents of HPLC-gradient grade and all other analyticalreagent grade chemicals were purchased from Sigma (Milan, Italy). The solutions were prepared in deionized water produced by a Purelab Classic system (Elga Labwater, Marlow, UK). Standards for (+)-catechin, anthocyanins and trans-resveratrol were supplied from Extrasynthèse (Genay, France), volatiles from Sigma, and hydroxycinnamoyl tartaric acids (HCTs) from Fluka (Buchs, Switzerland).

Spectrophotometric methods. Three replicates of 10 berries each were randomly sampled and treated as described by $\mathrm{Di}$ Stefano and Cravero (1991). Once the 10 berries were weighed, the skins and seeds were obtained, weighed, and placed separately in two different flasks containing $25 \mathrm{~mL}$ and $10 \mathrm{~mL}$, respectively, of a hydroalcoholic buffer $\left(12 \% \mathrm{v} / \mathrm{v}\right.$ ethanol, $5 \mathrm{~g} \mathrm{~L}^{-1}$ tartaric acid, $2 \mathrm{~g} \mathrm{~L}^{-1}$ sodium metabisulfite, adjusted to $\mathrm{pH} 3.2$ with $1 \mathrm{~mol} \mathrm{~L}^{-1}$ sodium hydroxide) (Río Segade et al., 2013). The skin extract was obtained by homogenization for $1 \mathrm{~min}$ at $8000 \mathrm{rpm}$ using an Ultra-Turrax T25 (IKA Labortechnik, Staufen, Germany) and centrifugation at $3000 \times \mathrm{g}$ at $20^{\circ} \mathrm{C}$. The seeds were macerated at $25^{\circ} \mathrm{C}$ for 7 days and the extract was then separated for the subsequent analysis (Río Segade et al., 2013).

Phenolic compounds of berry skins (sk) and seeds (s) were determined by spectrophotometry (Di Stefano and Cravero, 1991) using a UV-1800 spectrophotometer (Shimazdu Scientific Instruments Inc., Columbia, MD, USA). Absorbance at $280 \mathrm{~nm}\left(\mathrm{~A}_{280}\right)$ was determined directly in the diluted sample. Total anthocyanins index (TAI) was determined using a hydroalcoholic solution (ethanol: water: $37 \% \mathrm{HCl}, 70: 30: 1$ $\mathrm{v} / \mathrm{v} / \mathrm{v}$ ) and absorbance was measured at $540 \mathrm{~nm}$. TAI was expressed as $\mathrm{mg}$ malvidin-3-glucoside chloride $\mathrm{kg}^{-1}$ berries ( $\mathrm{Di}$ Stefano and Cravero, 1991). Proanthocyanidins (PRO) were determined after acid hydrolysis with heating (Bate-Smith reaction) using a ferrous salt $\left(\mathrm{FeSO}_{4}\right)$ as catalyst. They were expressed as $\mathrm{mg}$ cyanidin chloride $\mathrm{kg}^{-1}$ berries (Torchio et al., 2010). Flavanols reactive to vanillin (FRV) were determined following the methodology proposed by $\mathrm{Di}$ Stefano and Cravero (1989), and they were expressed as $\mathrm{mg}(+)$-catechin $\mathrm{kg}^{-1}$ berries.

Anthocyanin profile. The determination of individual anthocyanins in the skin extracts was performed after reversephase solid-phase extraction using a 1-g Sep-Pak $\mathrm{C}_{18}$ cartridge (Waters Corporation, Milford, MA) and elution with methanol (Rolle et al., 2013a). The HPLC - Diode Array Detector (DAD) system and chromatographic conditions have been previously described (Rolle et al., 2013a). A LiChroCART analytical column $(25 \mathrm{~cm} \times 0.4 \mathrm{~cm}$ i.d.) (Merck, Darmstadt, Germany) packed with LiChrospher 100 RP-18 5- $\mu$ m particles (Alltech, Deerfield, IL) was used. The following mobile phases were used: solvent $\mathrm{A}, 10 \% \mathrm{v} / \mathrm{v}$ formic acid in water; solvent B, 10\% v/v formic acid with $50 \% \mathrm{v} / \mathrm{v}$ methanol in water. The solvent flow rate was $1 \mathrm{~mL} / \mathrm{min}$, and the column temperature was $20^{\circ} \mathrm{C}$. A linear gradient was used starting at $72 \% \mathrm{~A}$ and decreasing to $55 \%$ $\mathrm{A}$ in $15 \mathrm{~min}, 30 \% \mathrm{~A}$ in $20 \mathrm{~min}, 10 \% \mathrm{~A}$ in $10 \mathrm{~min}, 1 \% \mathrm{~A}$ in $5 \mathrm{~min}$ and then back to $72 \% \mathrm{~A}$ in $3 \mathrm{~min}$. An equilibrium time of 10 min was used (Rolle and Guidoni, 2007). Data treatment was carried out using the ChromQuest chromatography data system (ThermoQuest, San Jose, CA). Identification of the free forms of anthocyanins was performed by comparison with external standards. The acylated forms of anthocyanins were identified by matching the DAD spectrum at $520 \mathrm{~nm}$ and retention time of each chromatographic peak and by comparing these data with those available in the literature (Pomar et al., 2005). The percentages of individual anthocyanins were determined by comparing the area of each individual peak with the total peak area. Each replicate was analyzed in duplicate.

Hydroxycinnamoyl tartaric acids. Three replicates of 10 berries each were processed as described by Ferrandino and Guidoni (2010). The skins were immersed into the hydroalcoholic solution buffered at $\mathrm{pH} 3.2$, and incubated for 72 h at $30^{\circ} \mathrm{C}$. The berry skin extract was diluted 1.1-fold with $1 \mathrm{~mol}$ $\mathrm{L}^{-1}$ phosphoric acid and filtered through $0.2 \mu \mathrm{m}$ hydrophilic polypropylene (GHP) membrane filters (Pall Corporation, New York, NY). The HPLC-DAD system and analytical column used for anthocyanins were again used to determine the HCTs. The chromatographic conditions have been previously reported in the literature (Ferrandino et al., 2012). The mobile phases were as follows: $\mathrm{A}, 10^{-3} \mathrm{~mol} \mathrm{~L}^{-1}$ phosphoric acid; $\mathrm{B}$, methanol. A linear gradient was established between 5 and $100 \%$ B over 49 $\mathrm{min}$ at a flow rate of $0.48 \mathrm{~mL} \mathrm{~min}^{-1}$. After the identification on the basis of the DAD spectra at $320 \mathrm{~nm}$ and retention times, $\mathrm{p}$ - 
142

coumaroyltartaric acid, caffeoyltartaric acid, and transferuloyltartaric acid were quantified as p-coumaric acid, caffeic acid, and ferulic acid equivalents, respectively. Then, the results were multiplied by the ratio between the molecular weight of each compound and the molecular weight of p-coumaric acid, caffeic acid, and ferulic acid for the p-coumaroyl, caffeoyl, and feruloyl derivatives, respectively. The total HCT concentration ( $\mathrm{mg} \mathrm{kg}^{-1}$ berries) was calculated as the sum of the concentrations of the individual compounds. HCT percentages were calculated. Each replicate was analyzed in duplicate.

trans-Resveratrol. Two replicates of 20 berries each were used. For each replicate, the skins were manually removed from frozen berries and then freeze-dried. $1 \mathrm{~g}$ of freeze-dried skins was treated as reported by Vincenzi et al. (2013). Briefly, the skins were immersed into a solution containing $40 \mathrm{~mL}$ methanol, $50 \mu \mathrm{L}$ hydrochloric acid and $250 \mu \mathrm{L}$ of an internal standard (transhydroxystilbene, $200 \mathrm{mg} \mathrm{L}^{-1}$ in ethanol). After Ultra-Turrax homogenization, the sample was stirred for $48 \mathrm{~h}$ at room temperature in the dark. The polyphenol-containing methanolic solution was recovered by centrifugation $(5000 \times \mathrm{g}, 5 \mathrm{~min})$ and almost completely evaporated to dryness using a vacuum rotavapor (Buchi R-210, Switzerland) at $35^{\circ} \mathrm{C}$. The residue obtained was suspended in $20 \mathrm{~mL}$ water, and stilbene compounds were extracted twice with $10 \mathrm{~mL}$ ethyl acetate for 15 min. The upper organic phase containing stilbenes was carefully recovered, dried by adding anhydrous sodium sulphate, filtered through Whatman $589 / 3$ paper and completely evaporated to dryness under a vacuum at $35^{\circ} \mathrm{C}$. The residue was then dissolved in $2 \mathrm{~mL}$ methanol and $50 \mathrm{mmol} \mathrm{L}^{-1}$ formic acid $(1: 1, \mathrm{v} / \mathrm{v})$, and the extract was centrifuged at $14000 \times \mathrm{g}$ for $10 \mathrm{~min}$.

The HPLC-Dual Band UV system and chromatographic conditions have been previously reported in the literature (Vincenzi et al., 2013). trans-Resveratrol was separated on the analytical column previously described for the anthocyanins and HCTs. The mobile phases were: solvent A, $50 \mathrm{mmol} \mathrm{L}^{-1}$ formic acid; solvent $\mathrm{B}$, methanol. The solvent flow rate was $1 \mathrm{~mL} \mathrm{~min}^{-1}$, and the column temperature was $40{ }^{\circ} \mathrm{C}$. A linear gradient was used, starting at $0 \% \mathrm{~B}$ and increasing to $10 \% \mathrm{~B}$ in $3 \mathrm{~min}, 30 \% \mathrm{~B}$ in $5 \mathrm{~min}, 44 \% \mathrm{~B}$ in $35 \mathrm{~min}, 55 \% \mathrm{~B}$ in $2 \mathrm{~min}, 75 \% \mathrm{~B}$ in $15 \mathrm{~min}$, and $100 \% \mathrm{~B}$ in $1 \mathrm{~min}$, and then returning to $0 \% \mathrm{~B}$ in $3 \mathrm{~min}$. The content of trans-resveratrol was expressed as $\mu \mathrm{g} \mathrm{g}^{-1}$ skin. Each replicate was analyzed in duplicate.

Free volatile compounds. For each sample, two hundred berries were processed following the procedure proposed by $\mathrm{Di}$ Stefano (1991) and summarized by Rolle et al. (2012). The berries were deseeded and the pulp was separated from the skin with the addition of sodium metabisulfite $(50 \mathrm{mg})$. The skins were treated with $20 \mathrm{~mL}$ methanol to avoid the enzymatic reactions. The pulps and skins were crushed separately under a nitrogen atmosphere with a laboratory blender (Waring Laboratory, Torrington, CT). The skin and pulp homogenates were then combined and centrifuged twice $(7000 \times \mathrm{g}, 15 \mathrm{~min}$, $\left.4^{\circ} \mathrm{C}\right)$, washing the solid residue with tartaric acid buffer $(\mathrm{pH}$ 3.2). The extract $(250 \mathrm{~mL})$ was then clarified using a pectolytic enzyme $(100 \mathrm{mg})$ without glycosidase activity (Rapidase X-Press, DSM, The Netherlands) at room temperature for 2 h. 1Heptanol was added to the sample as an internal standard (200 $\mu \mathrm{L}, 44 \mathrm{mg} \mathrm{L}^{-1}$ in $10 \% \mathrm{v} / \mathrm{v}$ ethanol). Afterwards, an aliquot (100 $\mathrm{mL}$ for white grapes or $50 \mathrm{~mL}$ for red grapes, $n=2)$ was then loaded onto a 1-g Sep-Pak C 18 RP-SPE cartridge (Waters Corporation). Free aroma compounds were eluted with $12 \mathrm{~mL}$ dichloromethane. The eluate was dried over anhydrous sodium sulphate, concentrated to approximately $200 \mu \mathrm{L}$ under a stream of nitrogen and immediately analysed by GC-MS.

The GC-MS system and chromatographic conditions were previously reported by Rolle et al. (2012). A DB-WAXETR capillary column $(30 \mathrm{~m} \times 0.25 \mathrm{~mm}, 0.25 \mu \mathrm{m}, \mathrm{J} \& \mathrm{~W}$ Scientific Inc., Folsom, CA) was used. The injection port temperature was $250^{\circ} \mathrm{C}$, the ion source temperature was $240^{\circ} \mathrm{C}$, and the interface temperature was $230^{\circ} \mathrm{C}$ (solvent delay of $6.5 \mathrm{~min}$ ). The temperature program started at $40^{\circ} \mathrm{C}$ for $5 \mathrm{~min}$, and increased at a rate of $2{ }^{\circ} \mathrm{C} / \mathrm{min}$ to $200{ }^{\circ} \mathrm{C}$ for $10 \mathrm{~min}$ and at $5{ }^{\circ} \mathrm{C} / \mathrm{min}$ to $220^{\circ} \mathrm{C}$. The oven was then held at $220^{\circ} \mathrm{C}$ for $5 \mathrm{~min}$ before returning to the initial temperature. The detection was carried out by electron impact mass spectrometry in total ion current (TIC) mode, using an ionization energy of $70 \mathrm{eV}$. The mass acquisition range was $m / z$ 30-330. Semi-quantitative data $\left(\mu \mathrm{g} \mathrm{kg}^{-1}\right.$ berries) were obtained by measuring the relative peak area of each identified compound, according to the NIST database (http://webbook.nist.gov/chemistry/), in relation to that of the added internal standard. Each replicate was analysed in duplicate.

\section{Statistical analysis}

Statistical analyses were performed using the SPSS Statistics software package (version 19.0, IBM Corporation, Armonk, NY). The Tukey-b test (at $p<0.05$ ) was used to establish significant differences by one-way analysis of variance (ANOVA).

\section{Results}

Table 1 shows the sugar content and berry characteristics for the four table grape varieties analyzed at harvest. The ripeness reached was in agreement with historical data for these cultivars (data not shown). In general, the richest grapes in soluble solids, evaluated as juice ${ }^{\circ}$ Brix degree, corresponded to the white 'Timpuriu de Cluj' variety, which was associated also with the lowest average berry weight. No significant differences were found in average berry skin and seed weight among the varieties studied.

\section{Phenolic content}

According to the values of $\mathrm{A}_{280}$, the red 'Napoca' variety contains significantly higher amounts of total skin polyphenols when compared to the other varieties (Table 2). Among others, this fact could be due to the higher richness in total anthocyanins for 'Napoca' with respect to 'Someşan' (Table 3). 'Someşan' grapes presented high values of the PRO index in the skins, but the lowest values found in the seeds.

The white 'Timpuriu de Cluj' variety showed high amounts of total skins and seeds polyphenols, especially for oligomeric tannins that were evaluated by the FRV index (Rolle et al., 2013b). On the opposite, 'Aromat de Iaşi' grapes showed significantly lower values of the PRO and FRV indices in the skin than the other varieties.

\section{Anthocyanin content}

Table 3 shows the total anthocyanin content and profile of the two red grape varieties. The 'Napoca' variety showed a significantly higher content of total anthocyanins (as $\mathrm{mg} \mathrm{kg}^{-1}$ berries and $\mathrm{mgg}^{-1}$ skin) than the 'Someşan' variety. The 
Table 1. Sugar content and berry characteristics of table grape varieties at harvest

\begin{tabular}{llccccc}
\hline Skin color & Variety & $\begin{array}{c}\text { Harvest date } \\
(2011)\end{array}$ & ${ }^{\circ}$ Brix & $\begin{array}{c}\text { Average berry } \\
\text { weight }(\mathrm{g})\end{array}$ & $\begin{array}{c}\text { Average berry } \\
\text { skin weight }(\mathrm{mg})\end{array}$ & $\begin{array}{c}\text { Average berry } \\
\text { seed weight }(\mathrm{mg})\end{array}$ \\
\hline \multirow{2}{*}{ White } & 'Aromat de Iaşi' & Sept 13 & $16.5 \pm 0.4$ & $2.95 \pm 0.02 \mathrm{ab}$ & $270 \pm 111$ & $82 \pm 49$ \\
& 'Timpuriu de Cluj' & Sept 05 & $20.9 \pm 1.6$ & $2.42 \pm 0.16 \mathrm{a}$ & $256 \pm 16$ & $66 \pm 11$ \\
\multirow{2}{*}{ Red } & 'Napoca' & Aug 29 & $16.0 \pm 0.5$ & $3.38 \pm 0.16 \mathrm{~b}$ & $327 \pm 12$ & $98 \pm 20$ \\
& 'Someșan' & Sept 13 & $14.4 \pm 0.8$ & $2.66 \pm 0.60 \mathrm{a}$ & $425 \pm 40$ & $84 \pm 1$ \\
\hline \multicolumn{2}{c}{$p$ value } & & - & 0.014 & 0.077 & 0.629
\end{tabular}

Values are expressed as average \pm standard deviation $\left(n=3\right.$ for ${ }^{\circ}$ Brix, $n=30$ for all other parameters). Different letters within the same column indicate significant differences (Tukey-b test; $p<0.05$ ).

Table 2. Phenolic composition of berry skins and seeds of table grape varieties

\begin{tabular}{|c|c|c|c|c|c|c|}
\hline \multirow{2}{*}{ Variety } & \multicolumn{2}{|c|}{$\mathrm{A}_{280}\left(\mathrm{~kg}^{-1}\right.$ berries $)$} & \multicolumn{2}{|c|}{ PRO (mg kg ${ }^{-1}$ berries) } & \multicolumn{2}{|c|}{ FRV (mg kg ${ }^{-1}$ berries) } \\
\hline & skins & seeds & skins & seeds & skins & seeds \\
\hline 'Aromat de Iaşi' & $13.4 \pm 1.6 \mathrm{a}$ & $15.3 \pm 3.0$ & $791 \pm 106 a$ & $854 \pm 177$ & $573 \pm 37 a$ & $1,109 \pm 77 \mathrm{c}$ \\
\hline 'Timpuriu de Cluj' & $25.3 \pm 1.4 b$ & $22.5 \pm 4.6$ & $1,601 \pm 149 b$ & $898 \pm 130$ & $1,171 \pm 216 b$ & $1,189 \pm 169 c$ \\
\hline 'Napoca' & $33.2 \pm 1.6 \mathrm{c}$ & $17.6 \pm 1.9$ & $1,866 \pm 18 b$ & $1,043 \pm 115$ & $1,134 \pm 71 b$ & $837 \pm 10 b$ \\
\hline 'Someşan' & $21.5 \pm 3.5 b$ & $13.9 \pm 1.8$ & $1,912 \pm 356 b$ & $714 \pm 153$ & $992 \pm 235 b$ & $580 \pm 75 a$ \\
\hline$p$ value & $<0.001$ & 0.067 & $<0.001$ & 0.179 & 0.007 & 0.001 \\
\hline
\end{tabular}

Values are expressed as average \pm standard deviation $(n=3)$. Different letters within the same column indicate significant differences (Tukey-b test; $\mathrm{p}<0.05)$, $\mathrm{A}_{280}=$ absorbance measured at $280 \mathrm{~nm}, \mathrm{PRO}=$ proanthocyanidins, $\mathrm{FRV}=$ flavanols reactive to vanillin .

Table 3. Anthocyanin content and profile of berry skins of table grape varieties

\begin{tabular}{|c|c|c|c|c|c|c|c|c|c|c|}
\hline \multirow{2}{*}{ Variety } & \multicolumn{2}{|c|}{ Total anthocyanins index } & \multicolumn{8}{|c|}{ Percentage of anthocyanin forms (\%) } \\
\hline & $\mathrm{mg} \mathrm{kg}^{-1}$ berries & $\mathrm{mg} \mathrm{g}^{-1}$ skins & $\sum$ delphinidin-G & $\sum$ cyanidin-G & $\Sigma$ petunidin-G & $\Sigma$ peonidin-G & $\sum$ malvidin-G & $\Sigma-G$ & $\sum$ acetyl-G & $\sum$ cinnamoyl-G \\
\hline 'Napoca' & $380 \pm 25$ & $3.93 \pm 0.20$ & $3.8 \pm 0.2$ & $2.6 \pm 0.2$ & $5.5 \pm 0.1$ & $29.1 \pm 1.7$ & $59.0 \pm 2.1$ & $71.4 \pm 1.7$ & $3.9 \pm 0.2$ & $24.6 \pm 1.5$ \\
\hline 'Someşan' & $151 \pm 24$ & $0.93 \pm 0.02$ & $5.7 \pm 1.9$ & $4.1 \pm 2.6$ & $5.4 \pm 0.8$ & $30.4 \pm 2.4$ & $54.5 \pm 2.9$ & $96.4 \pm 0.4$ & $0.9 \pm 0.1$ & $2.7 \pm 0.3$ \\
\hline$p$ value & 0.002 & $<0.001$ & 0.150 & 0.177 & 0.102 & 0.015 & 0.006 & $<0.001$ & $<0.001$ & $<0.001$ \\
\hline
\end{tabular}

Values are expressed as average \pm standard deviation $(n=3) . \mathrm{G}=3$-glucoside.

Table 4. Skin hydroxycinnamoyl tartaric acids and trans-resveratrol contents of berry skins of table grape varieties

\begin{tabular}{lccccccc}
\hline Variety & $\begin{array}{c}\text { Total HCTs } \\
\left(\mathrm{mg} \mathrm{kg}^{-1} \text { berries }\right)\end{array}$ & $\begin{array}{c}\text { trans-caffeoylT } \\
(\%)\end{array}$ & $\begin{array}{c}\text { cis-p-coumaroylT } \\
(\%)\end{array}$ & $\begin{array}{c}\text { trans-p- } \\
\text { coumaroylT (\%) }\end{array}$ & $\begin{array}{c}\text { trans-feruloylT } \\
(\%)\end{array}$ & $\begin{array}{c}\text { p-coumaroylT } \\
\text { / caffeoylT } \\
\text { ratio }\end{array}$ & $\begin{array}{c}\text { trans-resveratrol } \\
\left(\mu \mathrm{gg}^{-1} \text { skin }\right)\end{array}$ \\
\hline 'Aromat de Iaşi & $80.3 \pm 16.5 \mathrm{a}$ & $41.3 \pm 2.8 \mathrm{~b}$ & $15.9 \pm 1.6 \mathrm{~b}$ & $41.4 \pm 2.0 \mathrm{~b}$ & $1.4 \pm 0.4 \mathrm{~b}$ & $1.39 \pm 0.17 \mathrm{~b}$ & $44.4 \pm 5.9$ \\
'Timpuriu de Cluj' & $181.6 \pm 10.9 \mathrm{c}$ & $34.8 \pm 1.2 \mathrm{a}$ & $14.8 \pm 0.3 \mathrm{~b}$ & $48.5 \pm 1.1 \mathrm{~d}$ & $1.8 \pm 0.3 \mathrm{~b}$ & $1.82 \pm 0.09 \mathrm{c}$ & $71.0 \pm 10.3$ \\
'Napoca' & $183.2 \pm 17.4 \mathrm{c}$ & $58.8 \pm 0.4 \mathrm{c}$ & $8.3 \pm 0.3 \mathrm{a}$ & $32.3 \pm 0.2 \mathrm{a}$ & $0.7 \pm 0.1 \mathrm{a}$ & $0.69 \pm 0.01 \mathrm{a}$ & $46.2 \pm 6.3$ \\
'Someşan' & $131.4 \pm 19.9 \mathrm{~b}$ & $39.0 \pm 0.8 \mathrm{~b}$ & $15.2 \pm 1.6 \mathrm{~b}$ & $45.2 \pm 0.9 \mathrm{c}$ & $0.6 \pm 0.1 \mathrm{a}$ & $1.55 \pm 0.05 \mathrm{~b}$ & $60.5 \pm 21.5$ \\
\hline \multicolumn{1}{c}{$p$ value } & $<0.001$ & $<0.001$ & $<0.001$ & $<0.001$ & 0.002 & $<0.001$ & 0.260 \\
\hline
\end{tabular}

Values are expressed as average \pm standard deviation (HCTs $n=3$; trans-resveratrol $n=2$ ). Different letters within the same column indicate significant differences (Tukey-b test; $p<0.05$ ).

anthocyanin profile was similar for the two varieties considered, with significant differences in the free forms only for peonidin and malvidin. In particular, the percentage of cinnamoylglucoside forms was high in 'Napoca' grapes (about $25 \%$ of the total content), whereas the relative abundance of acylated forms was quite low in 'Someşan' grapes.

\section{HCTs and trans-resveratrol content}

Total content and profile of HCTs in the skins are shown in Table 4. 'Napoca' and 'Timpuriu de Cluj' varieties presented a significantly higher total skin HCTs content (more than $180 \mathrm{mg} \mathrm{kg}^{-1}$ ) while this content in 'Aromat de Iaşi' grapes was only $80 \mathrm{mg} \mathrm{kg}^{-1}$. The trans-caffeoyltartaric acid percentage ranged from $34.8 \%$ of 'Timpuriu de Cluj' to $58.8 \%$ of 'Napoca'. Instead, trans-p-coumaroyltartaric acid showed the lowest relative abundance in the latter variety (8.3\%). The white varieties showed proportions of trans-feruloyltartaric acid above $1 \%$ of total HCTs, while the percentages achieved in the red varieties were not higher than $0.7 \%$. The ratio between the sum of $\mathrm{p}$ coumaroyltartaric acids and trans-caffeoyltartaric acids was higher than 1.3 in all the varieties except for 'Napoca' $(0.69)$.

The highest skin contents of trans-resveratrol were found in 'Timpuriu de Cluj' grapes (71.0 $\mathrm{g} \mathrm{g} \mathrm{g}^{-1}$ skin), although the differences were not significant among varieties (Table 4).

\section{Aroma compounds}

Twenty-three free volatile compounds were identified and quantified (Table 5). As expected, most of the free aroma compounds identified were found in the 'Aromat de Iaşi' variety. The most abundant free volatile compound in this variety was geraniol, which represented about $38 \%$ of total content, followed by diol 1 , linalool and geranic acid that represented about $11 \%$, $10 \%$, and $8 \%$, respectively. These four aroma compounds were not found in the other white variety studied, whereas diol 1 and geranic acid were found only in 'Aromat de Iaşi'. This variety was also characterized by a large amount of geraniol $\left(520 \mathrm{ug} \mathrm{kg}^{-1}\right.$ 
Table 5. Free volatile compounds of table grape varieties

\begin{tabular}{|c|c|c|c|c|c|c|c|c|c|}
\hline \multirow{2}{*}{$\begin{array}{l}\text { Free compound ( } \mathrm{ggkg}^{1} \text { berries) } \\
\text { isoamyl alcohol }\end{array}$} & \multicolumn{2}{|c|}{ ‘Aromat de Iaşi' } & \multicolumn{2}{|c|}{ 'Timpuriu deCluj' } & \multicolumn{2}{|c|}{ 'Napoca' } & \multicolumn{2}{|c|}{ 'Someşan' } & \multirow[t]{2}{*}{ p-value } \\
\hline & & nd & & nd & & nd & 2.5 & \pm 3.2 & \\
\hline (E)-2-hexenal & $6.7 \pm$ & \pm 2.5 & & nd & & nd & 10.0 & \pm 6.9 & 0.584 \\
\hline 1-hexanol & $38.0 \pm$ & $\pm 3.9 \mathrm{a}$ & 146.0 & $\pm 6.0 \mathrm{bc}$ & 120.1 & $\pm 4.1 \mathrm{~b}$ & 167.0 & $\pm 18.6 \mathrm{c}$ & $<0.001$ \\
\hline (Z)-3-hexen-1-ol & & nd & 27.0 & $\pm 4.2 \mathrm{a}$ & 25.3 & $\pm 5.5 \mathrm{a}$ & 59.4 & $\pm 0.9 \mathrm{~b}$ & 0.006 \\
\hline (E)-2-hexen-1-ol & $46.0 \pm$ & $\pm 2.5 \mathrm{a}$ & 144.4 & $\pm 8.5 \mathrm{~b}$ & 61.1 & $\pm 3.7 \mathrm{a}$ & 120.9 & $\pm 11.3 \mathrm{~b}$ & $<0.001$ \\
\hline cis-furanic linalool oxide & $3.2 \pm$ & \pm 1.2 & & nd & & nd & & nd & \\
\hline trans-furaniclinalool oxide & $13.5 \pm$ & \pm 0.2 & & nd & & nd & & nd & \\
\hline linalool & $131.7 \pm$ & \pm 41.1 & & nd & & nd & 24.4 & \pm 1.1 & 0.066 \\
\hline geranial & $7.6 \pm$ & \pm 1.7 & & nd & & nd & & nd & \\
\hline trans-pyranic linalool oxide & $48.0 \pm$ & \pm 4.6 & & nd & & nd & 42.3 & \pm 9.0 & 0.506 \\
\hline cis-pyranic linalool oxide & $55.9 \pm$ & \pm 6.8 & & nd & & nd & 18.8 & \pm 1.5 & 0.017 \\
\hline geraniol & $520.0 \pm$ & $\pm 193.2 \mathrm{~b}$ & & nd & 8.7 & $\pm 0.7 \mathrm{a}$ & 97.1 & $\pm 24.1 \mathrm{a}$ & 0.038 \\
\hline hexanoic acid & $54.1 \pm$ & $\pm 4.6 \mathrm{a}$ & 140.2 & $\pm 6.5 \mathrm{~b}$ & 116.7 & $\pm 4.3 \mathrm{~b}$ & 116.7 & $\pm 10.4 \mathrm{~b}$ & $<0.001$ \\
\hline benzylalcohol & & nd & & nd & 24.6 & \pm 27.1 & 20.3 & \pm 3.8 & 0.846 \\
\hline 2-phenylethanol & $21.8 \pm$ & \pm 2.2 & 28.0 & \pm 3.8 & 21.0 & \pm 4.2 & 18.4 & \pm 3.2 & 0.175 \\
\hline (E)-2-hexenoic acid & & nd & & nd & 56.3 & \pm 0.7 & 167.0 & \pm 13.2 & 0.007 \\
\hline 4vinylguaiacol & $14.3 \pm$ & \pm 3.5 & 40.9 & \pm 24.9 & 9.5 & \pm 1.5 & 30.0 & \pm 19.0 & 0.308 \\
\hline diol 1 & $154.5 \pm$ & \pm 18.0 & & nd & & nd & & nd & \\
\hline 1-hydroxylinalool & $12.2 \pm$ & \pm 0.0 & & nd & & nd & & nd & \\
\hline diol 2 & $61.4 \pm$ & \pm 16.8 & & nd & & nd & & nd & \\
\hline $\mathrm{OH}$-geraniol & $6.0 \pm$ & \pm 0.5 & & nd & & nd & & nd & \\
\hline 3,7-dimethyl-6-octenal & $46.6 \pm$ & \pm 3.8 & & nd & & nd & & nd & \\
\hline geranic acid & $113.2 \pm$ & \pm 5.3 & & nd & & nd & & nd & \\
\hline
\end{tabular}

Volatile compounds are ordered by their retention time. Values are expressed as average \pm standard deviation $(n=2)$; nd $=$ not detected. Different letters within the same column indicate significant differences between the varieties (Tukey-b test; $p<0.05$ ).

berries), which was significantly different from all the varieties studied. The aroma profiles of 'Timpuriu de Cluj' and 'Someşan' grapes were characterized by high contents of 1-hexanol and $(E)$ 2-hexen-1-ol, while (E)-2-hexenoic acid and isoamyl alcohol were also found in the 'Someşan' variety. In 'Napoca' grapes prevailed 1-hexanol, (E)-2-hexen-1-ol, hexanoic acid, and (E)-2-hexenoic acid with about $27 \%, 26 \%$, and $13 \%$ of total content, respectively.

\section{Discussion}

According to the OIV Resolution VITI 1/2008 (OIV Standard on Minimum Maturity Requirements for Table Grapes), the table grape analysed in this study can be considered ripe at harvest. However, the ripeness level was different, particularly among white table grape varieties, and the soluble solids content was higher for 'Napoca' and 'Timpuriu de Cluj' table grapes even at earlier dates than 'Someşan' and 'Aromat de Iaşi grapes, respectively. This seems to indicate longer maturity periods for the latter ones.

Berry weight and skin/pulp ratio are considered important factors for the table grape market. In this study, the skin weight/berry weight ratio varied between 9.1\% ('Aromat de Iaşi') and $10.6 \%$ ('Timpuriu de Cluj). These values are in agreement with those found in literature for other white table grapes (Rolle et al., 2011). Only 'Someşan' grapes showed higher values of this parameter (16.0\%), whereas 'Napoca' grapes were characterized by the heaviest berries. In red varieties, this ratio is particularly important because it is related to quality chemical parameters (Barbagallo et al., 2011; Roby et al., 2004; Rolle et al., 2015).

In addition to physical properties, the interest of table grape consumers focused more on the nutraceutical values, and in particular the phenolic composition gained attention (Parpinello et al., 2013). In this study, considering all the phenol compound classes $\left(\mathrm{A}_{280}\right)$, 'Timpuriu de Cluj' had the greatest amount of phenols among the white varieties while 'Napoca' among red varieties. With the exception of 'Aromat de Iasi', the contents of phenolic compounds were always higher in skins than in seeds. The skin/seed ratio for total phenols ranged from 1.12 ('Timpuriu de Cluj') and 1.89 ('Napoca'). This fact could be positive from a sensory point of view because of a softening effect on the mouthfeel in relation to a lower astringency perception. The seeds of 'Aromat de Iassi' were richer in total phenols than the skins in agreement with other table grape varieties (Baiano and Terracone, 2011). When compared with 'Muscat Hamburg' and 'Italia', which are ones of the most present varieties in the market for table grapes, the Romanian varieties studied here showed similar total contents of phenolic compounds (Liang et al., 2011; Río Segade et al., 2013; Rolle et al., 2015), although climate and growing zone may influence these results. Particularly, 'Aromat de Iaşi' and 'Timpuriu de Cluj' white table grape varieties were richer than 'Italia' grapes in high molecular weight flavanols (PRO) and oligomeric flavanols (FRV) in skins and seeds. Instead, 'Napoca' and 'Someşan' red table grape varieties were richer in oligomeric flavanols, but the content of high molecular weight flavanols was similar to 'Muscat Hamburg' grapes.

From the red grapes compositional point of view, a possible indicator of the grape color is the skin anthocyanin content, which is directly related to the visual color (Rolle and Guidoni, 2007). Therefore, this factor has a huge contribution in the skin color for commercialization and fresh consumption of grapes. The total anthocyanin content of the red varieties studied was 151 and $380 \mathrm{mg} \mathrm{kg}^{-1}$ berries. These contents are in agreement with those published in previous studies on other varieties 
(Crupi et al., 2012; Dami et al., 2006; Kamiloglu, 2011; Liang et al., 2011; Orak, 2006). The 'Napoca' variety had the highest amount of anthocyanins, with a prevalence of malvidin derivatives and high percentages of acylated anthocyanin forms, similar to the 'Regina nera' table grape cultivar (Rolle et al., 2013a). In the grape juice production, the phenolic content and the juice color are important factors, the latter also for the direct consumer perception (Kliewer, 1970). Therefore, special processing treatments were studied to achieve a higher phenolic content in the produced juices (Lima et al., 2015), and the use of phenolic-rich varieties such as 'Napoca' could give interesting products.

In winegrapes, smaller berries generally showed higher contents of anthocyanins (Barbagallo et al., 2011; Roby et al., 2004). For the 'Someșan' and 'Napoca' table grape varieties, this behavior was not detected. The results obtained in this study agreed with those observed in 'Muscat Hamburg' table grapes (Rolle et al., 2015).

The anthocyanin profile of grapes is primarily influenced by genetic factors, and the ratio among anthocyanin forms can be used for chemotaxonomical classifications (Carreno et al., 1997). In this study, many significant differences were found among the two varieties. Also the HCT profile could be a characteristic of the variety and could be used as a discriminating tool among cultivars (Ferrandino et al., 2012). The HCT compounds were yet less investigated in table grapes with respect to anthocyanins, flavanols, flavonols and stilbenes. 'Aromat de Iaşi' and 'Someşan' table grapes were characterized by a HCT content similar to those reported by Ferrandino et al. (2012) for winegrapes. Instead, the 'Timpuriu de Cluj' and 'Napoca' varieties were richer in these compounds. When compared with Muscat Hamburg table grapes (Ferrandino et al., 2012), all the Romanian varieties studied showed higher total HCT contents.

trans-Resveratrol content in the Romanian table grape varieties studied was in the range of winegrapes (Vincenzi et al., 2013). The beneficial effects of trans-Resveratrol on human health have been recognized, and the presence of relatively high amounts of this compound in table grapes is highly valued by consumers sensitized in the nutraceutical properties of foods.

Regarding aroma compounds, higher levels of linalool and geraniol in 'Aromat de Iaşi' variety may contribute to floral and fruity odour (Duan, et al. 2014). These terpenes are responsible for the aroma of Muscat grapes (Ruiz-García et al., 2014). Geraniol, linalool and $\alpha$-terpineol are prevalent in 'Tămâioasă românească with $17.6 \%, 38.5 \%$ and $43.7 \%$ respectively (Târdea, 2007). Although 'Aromat de Iaşi' was obtained from this last variety, $\alpha$-terpineol was not detected.

\section{Conclusions}

Among white grapes, the 'Timpuriu de Cluj' variety has an important content of phenolic compounds, which can contribute greatly to the overall nutraceutical value. This characteristic could be particularly appreciated by consumers, especially in white grapes. However, this variety showed an aroma profile composed of few volatile compounds. 'Aromat de Iaşi', instead, had the more complex aroma composition among the Romanian table grape varieties studied with a relevant content of geraniol.

Red varieties are gaining interest by consumers in the table grape market. In this sense, 'Napoca' red grapes could be appreciated because of their greater content of skin anthocyanins and also total skin HCTs. Furthermore, these grapes are characterized by the highest berry weight among the studied varieties. Despite the lower anthocyanin content, 'Someşan' grapes showed an aroma profile composed of more compounds with generally higher contents in relation to the other Romanian red variety studied. This study permitted to improve the knowledge of minor Romanian table grape varieties in order to permit a better exploitation of these cultivars.

\section{Acknowledgements}

This work was supported by European Social Fund, Human Resources Development Operational Programme 2007-2013, project no. POSDRU/159/1.5/S/132765.

\section{References}

Baiano A, Terracone C (2011). Varietal differences among the phenolic profiles and antioxidant activities of seven table grape cultivars grown in the south of Italy based on chemometrics. Journal of Agricultural and Food Chemistry 59:9815-9826.

Barbagallo MG, Guidoni S, Hunter JJ (2011). Berry size and qualitative characteristics of Vitis vinifera L. cv. Syrah. South African Journal of Enology and Viticulture 32:129-136.

Carreno J, Almela L, Martinez A, Fernadez-Lopez JA (1997). Chemotaxonomical classification of red table grapes based on anthocyanin profile and external colour. Lebensmittel-Wissenschaft und-Technologie 30:259-265.

Crupi P, Coletta A, Milella RA, Perniola R, Gasparro M, Genghi R, Antonacci D (2012). HPLC-DAD-ESI-MS analysis of flavonoid compounds in 5 seedless table grapes grown in Apulian region. Journal offood Science 77:C174C181.

Dami I, Ferree D, Prajitna A, Scurlock D (2006). A five-year study on the effect of cluster thinning on yield and fruit composition of Chambourcin'grapevines. HortScience 41(3):586-588.

Di Stefano R (1991). Proposal for a method of sample preparation for the determination of free and gycoside terpenes of grapes and wines. Bulletin del'OIV 721-722:219-223.

Di Stefano R, Cravero MC (1989). Metodi per lo studio dei polifenoli dei vini. L'Enotecnico 83-89.

Di Stefano R, Cravero MC (1991). Metodi per lo studio dei polifenoli dell'uva. Rivista di Viticoltura edi Enologia 44:37-45.

Dobrei A, Sala F, Mos V (2009). Local grapevine biotypes and varieties a source for biodiversity. Bulletin UASVM Horticulture 66(1):260-266.

Duan LL, Pan QH, Tang XJ, Yang Q, Jiang R, Shi Y, Duan CQ (2014). Characteristic aroma compounds in two new Vitis vinifera cultivars (table grapes) and impact of vintage and greenhouse cultivation. South African Journal of Enology and Viticulture 35(2):264 277.

Fenoll J, Manso A, Hellin P, Ruiz L, Flores P (2009). Changes in the aromatic composition of the Vitis vinifera grape Muscat Hamburg duringripening. Food Chemistry 114:420-428.

Ferrandino A, Carra A, RolleL, Schneider A,Schubert A (2012).Profiling of hydroxycinnamoyl tartrates and acylated anthocyanins in the skin of 34 Vitis vinifera genotypes. Journal of Agricultural and Food Chemistry 60(19):4931-4945. 
146

Ferrandino A, Guidoni S (2010). Anthocyanins, flavonols and hydroxycinnamates: an attempt to use them to discriminate Vitis vinifera L. cv 'Barbera' clones. European Food Research and Technology 230:417-427.

Georgiev V, Ananga A, Tsolova V (2014). Recent advances and uses of grape flavonoids as nutraceuticals. Nutrients 6(1):391-415.

Heim KE, Tagliaferro AR, Bobilya DJ (2002). Flavonoid antioxidants: chemistry, metabolism and structure-activity relationships. The Journal of Nutritional Biochemistry 13(10):572-584.

INSSE (2015). Romanian National Institute of Statistics. Retrieved 2015

October 4 from http://statistici.insse.ro/shop/index.jsp?page=tempo2\&lang=ro\&context=45.

Kamiloglu O (2011). Influence of some cultural practices on yield, fruit quality and individual anthocyanins of table grape cv. 'Horoz Karasi'. Journal of Animal and PlantSciences21(2):240-245.

Kliewer WM (1970). Effect of day temperature and light intensity on coloration of Vitis vinifera L grapes. Journal of the American Society of Horticultural Science 95:693-7.

Liang Z, Owens CL, Zhong G-Y, Cheng L (2011). Polyphenolic profiles detected in the ripe berries of Vitis vinifera germplasm. Food Chemistry 129:940-950.

Lima MDS, Dutra MDCP, Toaldo IM, Corrêa LC, Pereira GE, de Oliveira D, Bordignon-Luiz MT, Ninow JL (2015). Phenolic compounds, organic acids and antioxidant activity of grape juices produced in industrial scale by different processes of maceration. Food Chemistry 188:384-392.

Orak HH (2006). Total antioxidant activities, phenolics, anthocyanins, polyphenoloxidase activities and its correlation of some important red wine grape varieties which are grown in Turkey. Electronic Journal of Polish Agricultural Universities. Series Food Science and Technology 9:1-7.

Parpinello GP, Nunziatini G, Rombolà AD, Gottardi F, Versari A (2013). Relationship between sensory and NIR spectroscopy in consumer preference of table grape (cv Italia). Postharvest Biology and Technology 83:47-53.

Pomar F, Novo M, Masa A (2005). Varietal differences among the anthocyanin profiles of 50 red table grape cultivars studied by high performance liquid chromatography. Journal of Chromatography A 1094:34-41.

Río Segade S, Giacosa S, de Palma L, Novello V, Torchio F, Gerbi V, Rolle L (2013). Effect of the cluster heterogeneity on mechanical properties, chromatic indices and chemical composition of Italia table grape berries (Vitis vinifera L.) sorted by flotation. International Journal of Food Science and Technology 48:103-113.

Roby G, Harbertson JF, Adams D A, Matthews MA (2004). Berry size and vine water deficits as factors in winegrape composition: anthocyanins and tannins. Australian Journal of Grape and Wine Research 10:100107.
Rolle L, Giacosa S, Gerbi V, Bertolino M, Novello V (2013a). Varietal comparison of the chemical, physical, and mechanical properties of five colored table grapes. International Journal of Food Properties 16(3):598-612.

RolleL, GiacosaS, Gerbi V, Novello V (2011). Comparative study of texture properties, color characteristics, and chemical composition of ten white table-grape varieties. American Journal of Enology and Viticulture 62(1):49-56.

RolleL, GiacosaS, Torchio F, Perenzoni D, RíoSegadeS, Gerbi V, Mattivi F (2013b). Use of instrumental acoustic parameters of winegrape seeds as possible predictors of extractable phenolic compounds. Journal of Agricultural and Food Chemistry 61:8752-8764.

Rolle L, Giordano M, Giacosa S, Vincenzi S, Río Segade S, Torchio F, Perrone B, Gerbi V (2012). CIEL* $a^{*} b^{*}$ parameters of white dehydrated grapes as quality markers according to chemical composition, volatile profile and mechanical properties. Analytica Chimica Acta 732:105113.

Rolle L, Guidoni S (2007). Color and anthocyanin evaluation of red winegrapes by CIE L*, a*, $b^{*}$ parameters. International Journal of Vine and WineSciences 41(4):193-201.

Rolle L, Torchio F, GiacosaS, Río Segade S (2015). Berry density and size as factors related to the physicochemical characteristics of Muscat Hamburg table grapes (Vitisvinifera L.). Food Chemistry 173:105-113.

Ruiz-García L, Hellín P, Flores P, Fenoll J (2014). Prediction of Muscat aroma in table grape by analysis of rose oxide. Food Chemistry 154:151157.

Țârdea C (2007). Chimia și analiza vinului [Chemistry and wine analysis]. Ion Ionescu de la Brad(Ed), Iași.

Topalovic A, Godjevac D, Perovic N, Trifunovic S (2012). Comparative study of the phenolic composition of seeds from grapes cv Cardinal and Alphonse Lavallee during last month of ripening. Italian Journal of Food Science 24:159-166.

Torchio F, Cagnasso E, Gerbi V, Rolle L (2010). Mechanical properties, phenolic composition and extractability indices of Barbera grapes of different soluble solids contents from several growing areas. Analytica ChimicaActa 660(1):183-189.

Urcan DE, Lung ML, Giacosa S, Torchio F, Ferrandino A, Vincenzi S, Río Segade S, Pop N, Rolle L (2016). Phenolic substances, flavor compounds and textural properties of three native Romanian wine grape varieties. International Journal of Food Properties 19:76-98.

Vincenzi S, Tomasi D, Gaiotti F, Lovat L, Giacosa S, Torchio F, Río Segade S, Rolle L (2013). Comparative study of the resveratrol content of twenty-one Italian red grape varieties. South African Journal of Enology and Viticulture 34:30-35.

Xia EQ, Deng GF, Guo YJ, Li HB (2010). Biological activities of polyphenols from grapes. International Journal of Molecular Sciences 11(2):622-646. 